\title{
A case report of retiform hemangioendothelioma as pleural nodules with literature review
}

\author{
Qingqing Liu, Ruoyun Ouyang, Ping Chen and Rui Zhou*
}

\begin{abstract}
Retiform hemangioendothelioma $(\mathrm{RH})$ is a rare low-grade variant of angiosarcoma mostly reported on dermis or subcutaneously. A 30-year-old woman suffering from dry cough, dyspnea and pleural effusion has been described. Distinctive symptoms and lesions on high resolution computed tomography (HRCT) scan and common histological, immunological feature are discussed. Diagnosis was made by thoracoscopy as RH.
\end{abstract}

Keywords: Retiform hemangioendothelioma, Pleural effusion, Breast cancer, CD31, CD34, D2-40

\section{Background}

$\mathrm{RH}$ is known as a rare kind of low-grade malignant angiosarcoma with high rate of local recurrence and low potential of metastasis which is a sparsely distributed disease counting 35 cases (Table 1) whereas none of them is related to pleura or lung [1]. Given the lacking information of pleural RH, its clinical manifestation, HRCT presentation and thoracoscopic appearance of a female patient are presented. The definitive diagnosis was made due to pathological observation and immunochemical staining. The prognosis is unpredictable since the tumor can affect multiple organs [2]. Unfortunately, consensus has not been reached on if there is effective treatment to this tumor.

\section{Case presentation}

\section{Clinical history and radiology}

A 30-year-old female patient was admitted to pulmonary department because of dyspnea and dry cough denying chest pain, hemoptysis, fever, weight loss or other systemic symptoms. Her symptoms were stable and had not been given any medication prior to admission. Her chest X-ray by local hospital showed pleural effusion on the right side. She received modified radical mastectomy in 2006 removing a breast mass on her right chest. The biopsy confirmed a diagnosis of poorly-differentiated invasive ductal carcinoma with axillary lymph nodes metastasis therefore the

\footnotetext{
* Correspondence: zhourui2355@sina.com

Department of Internal Medicine, Second Xiangya Hospital of Central South University, 139 Renming Rd, Changsha, Hunan 410011, PR China
}

patient received adjuvant chemotherapy and radiotherapy. Her father died of liver cancer. The rest of her personal history, social history and the review of systems were unremarkable. Decreased vocal fremitus and dullness of percussion on her right thorax were detected in physical examination. No enlarged superficial lymph nodes were palpated and laboratory tests revealed normal level of carcino-embryonic antigen (CEA). Her ultrasonic examination of abdomen and pelvis cavity alarmed no metastatic signs. The patient's HRCT results showed merely pleural effusion on the right side (Fig. 1). No residual mass, enlarged lymph nodes of hilar or lesion on pleura were observed. Laboratory tests of her pleural effusion samples contained erythrocytes and leukocytes and it was exudates. Furthermore, cytological examination reported large amount of lymphocytes without atypical or carcinomatous cells. Scattered greyish variously sized nodes were discovered on costal pleura in thoracoscopy. The lesion presented themselves as exophytic masses surrounded by indistinctive borders with a tendency to fuse together. Pulmonary and diaphragmatic pleura were free from infiltration. Rechecking of chest X-ray complied with her former HRCT scan.

\section{Histology and immunohistochemistry}

Histological and immunological examination of biopsy specimen pictured disarranged, jagged, blood vessels of thin walls and slit-like fissures were prevailing. At higher magnification the vessels' walls were lined with highly nuclei/cytoplasm ratioed endothelial cells with minimal 
Table 1 Summary of clinical features of reported RH cases

\begin{tabular}{|c|c|c|c|c|c|c|}
\hline Author (N) & Age/Gender & Site & Immunochemistry & Metastasis & Treatment & Survival \\
\hline \multirow[t]{5}{*}{ Calonje (15) } & \multirow[t]{5}{*}{ 9-78/9 F,6 M } & 6:lower limbs & \multirow[t]{5}{*}{ ND } & \multirow[t]{5}{*}{$1 / 15$} & \multirow[t]{5}{*}{ ND } & \multirow[t]{5}{*}{ ND } \\
\hline & & 4:upper limbs & & & & \\
\hline & & 3:Trunk & & & & \\
\hline & & 1:Penis & & & & \\
\hline & & 1:Scalp & & & & \\
\hline Fukunaga (1) & $75 / F$ & Lower limb & $\begin{array}{l}\text { CD31, vimentin, UEA-1 (all), } \\
\text { CD34, f-VIII (part) }\end{array}$ & $0 / 1$ & ND & ND \\
\hline Duke (1) & $30 / F$ & Upper limb, trunk & CD31, f-VIII & $0 / 1$ & Excision & $>10$ years \\
\hline Samz-Trelles (1) & $11 / \mathrm{M}$ & Lower limb & Vimentin, f-VIII & $0 / 1$ & Excision & $>4$ years \\
\hline Schommer (1) & $73 / F$ & Trunk & CD31,UEA-1, f-VIII & $0 / 1$ & Excision, RT, IT & $>1$ year \\
\hline Darouti (1) & $32 / F$ & Lower limb & $f-V I I I$ & ND & ND & $>1.5$ years \\
\hline $\operatorname{Tan}(1)$ & $19 / F$ & Lower limb & ND & $0 / 1$ & Excision & $>14$ months \\
\hline loannidon (1) & $55 / F$ & Upper limb & CD31 & $0 / 1$ & Excision & $>4$ years \\
\hline \multirow[t]{4}{*}{ Parson (1) } & \multirow[t]{4}{*}{$17-71 / 4 \mathrm{~F}, 0 \mathrm{M}$} & 1:upper limb & CD31(4/4), & \multirow[t]{4}{*}{ ND } & \multirow[t]{4}{*}{ ND } & \multirow[t]{4}{*}{ ND } \\
\hline & & 1:trunk & D2-40(1/4), & & & \\
\hline & & 1:head & VEGFR3(0/4) & & & \\
\hline & & 1:lower limb & & & & \\
\hline Bhutoria (1) & $35 / F$ & Trunk & ND & Lymph node & Excision & ND \\
\hline Emberger (1) & $17 / M$ & Trunk & $\mathrm{CD} 31, \mathrm{D} 2-40$ & $0 / 1$ & Excision & $>3$ years \\
\hline Zhang (1) & $61 / F$ & Head & CD34, f-VIII, vimentin & $0 / 1$ & Excision(twice) & 6 months \\
\hline Aydıngöz (1) & $60 / F$ & Lower limb & ND & $0 / 1$ & Excision & $>2$ years \\
\hline Hirsh (1) & $44 / \mathrm{M}$ & Trunk & CD31 & $0 / 1$ & Resection,chemoradiation & $>36$ months \\
\hline Keiler (1) & $11 / F$ & Upper limb & ND & $0 / 1$ & Excision & ND \\
\hline O'Duffy (1) & 18/M & Head & ND & Lymph node & Excision, RT & ND \\
\hline Albertini(1) & $6 / F$ & Trunk & D2-40 & Lung & Excision & 6 months \\
\hline Choi (1) & 20/M & Upper limb & $f-V I I I$ & ND & Excision & ND \\
\hline Couceiro (1) & $50 / F$ & Upper limb & ND & ND & Excision & $>4$ years \\
\hline Mota (1) & $26 / F$ & Trunk & CD31, D2-40 & ND & Excision & ND \\
\hline Al-Faky & 9/F & Head & CD31, CD34, D2-40, f-VIII & ND & Excision & $>6$ years \\
\hline
\end{tabular}

$N D$ not documented, $M$ male, $F$ female, UEA-1 ulex europaeus agglutinin 1, $f$-VIII factor VIII-related antigen, $R T$ radiotherapy, IT immunotherapy

cytological atypia and mitosis. Atypical cells protruding into lumina mimicking "hobnail" appearance or endothelial papillae was absent as well as their invasion into adjacent tissues. Infiltration of lymphocytes was also rare (Fig. 2). Combined with immunohistochemical staining positive for CD31, CD34, D2-40 (Fig. 3) and negative for CrebB-2, GCDFP-15, CEA, CA15-3, S-100, Ki-67 and myogenin, which confirmed the diagnosis and ruled out the possibility of breast cancer and other diagnosis, a diagnosis of $\mathrm{RH}$ was established.

\section{Results}

According to our knowledge and clinical experience, endostatin was recommended for treatment. The patient revisited 6 months later with relieved symptoms when her HRCT showed diminished and encapsulated pleural effusion after receiving symptomatic treatment and passed away at home in 2013.

\section{Discussion}

Hemangioendothelioma (HE), an intermediate lesion between hemangioma and angiosarcoma, has been incipiently delineated as a kind of vascular tumor highlighted by its marginal biological features [3]. It generally appears on skin or in soft tissues and extensively includes HE of epithelioid, kaposiform, retiform, composite and pseudomyogenic (also known as epithelioid sarcoma-like HE) subgroups and papillary intralymphatic angioendothelioma (also known as Dabska tumor). Malignancy of pseudomyogenic HE has recently been re-recognized [4]. Definitive diagnosis of varied types of this tumor is based on histopathlological morphology and immunohistochemical markers [5]. HE on 


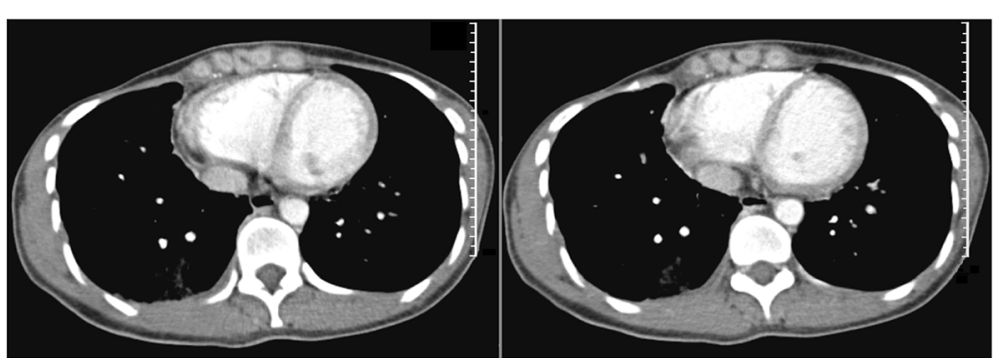

Fig. 1 HRCT scan of the patient before thoracoscopy. Small amount of unilateral pleural effusion was detected on the right side of the patient None visible pleural nodes were reported. (Opacity showed in the patient's right lung which has been proved to be bacterial infection because it disappeared after treatment of antibiotics)

pleura are limitedly documented as majority of them have been confirmed as epithelioid hemangioendothelioma (EH). Though EH favorably links to lung and pleura according to published cases, there has never been a description of its counterpart-retiform hemangioendothelioma on pleura.

Retiform hemangioendothelioma is a low-grade variant angiosarcoma which has been first introduced by Calonje in 1994 [6]. Hyperchromatic nuclei without mitosis suggests its intermediate characters [7] and indicates discrepant prognosis.

RH demonstrates a predilection for female adults [6]. The majority of RH cases have been described as lesions on trunk or limbs [8] whereas penis and scalp were occasionally involved [9]. Features of RH's lesion vary among individual patients expressing as masses, which is hyperhidrotic, or erosion $[8,10,11]$. Exophytic pattern seems to be more prevailing [8]. All the lesions in this patient were surrounded by "poor circumscription" as a presentation of its histological character.

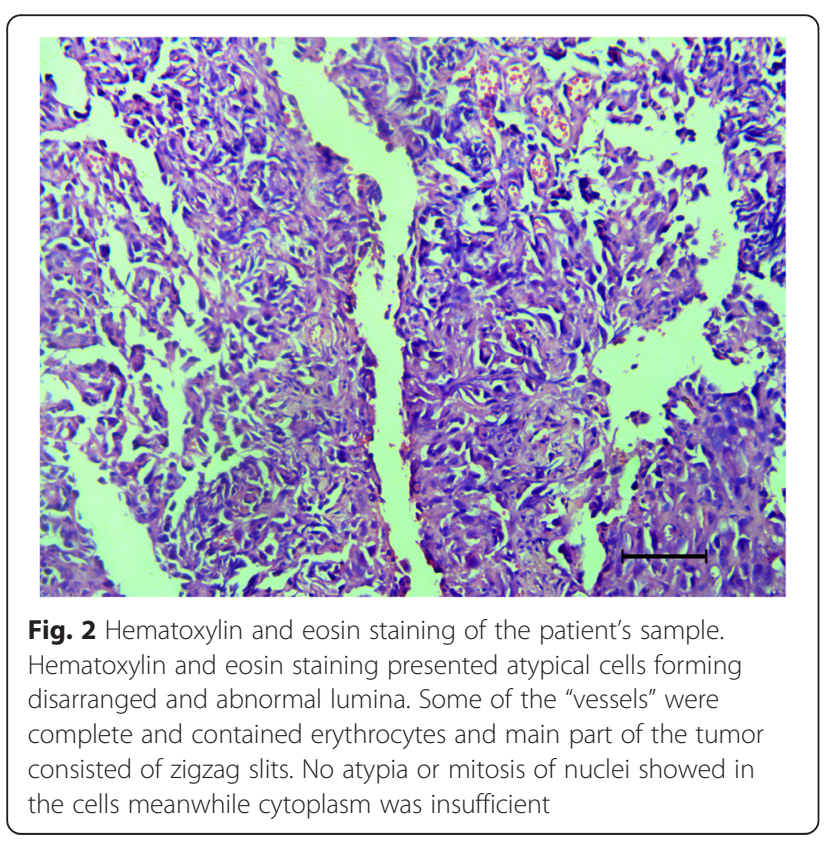

Histological diagnosis lays the foundation of clinical diagnosis also plays the key role in differentiating $\mathrm{RH}$ from angiosarcoma and other subtypes of hemangioendothelioma. RH comprises of blood vessels "weaving a net" by infiltrating into bundles of collagen. Endothelial cells fashion intraluminal papillea with scarce cytoplasm $[8,12]$. However, pathological sample in this case for histological examination may accidentally be a single component of "composite hemangioendothelioma" which contains retiform HE, epithelioid $\mathrm{HE}$, angiosarcoma, spindle cell hemangioma, lymphangioma, arteriovenous malformation [13] or part of these. This assumption is drawn from the fact that excision of gross sample has not be performed taking the fact that $\mathrm{EH}$ tends to form in lung into consideration [14].

Histochemical markers of RH include CD31, D2-40, CD34, factor VIII-related antigen [15, 16] among which CD34, factor VIII-related antigen have been consistently reported. CD34 and CD31 symbolize endothelial lineage and D2-40 expresses on other kinds of lymphatic hemangioendothelioma or hemangioma [17, 18]. Controversy, nevertheless, has been aroused by Amy Parson's



Fig. 3 Immunohistochemical staining of the patient's sample. Immunohistochemical staining for D2-40 expression was positive 
demonstration of 3 negative cases of D2-40 in 4 RH patients [19].

Though histological and clinical features permits differential diagnosis between $\mathrm{RH}$ and other vascular tumors [20], it shares a number of similarities with hobnail hemangioma which has been considered as it benign counterpart. However, hobnail hemangioma features shortage of papillae protruding into lumina and restricted location [21] while prominent lymphatic infiltration and extensive lesion (dermis and subcutis) are widely applied to make the RH diagnosis [22]. Moreover, definitive diagnosis of a papillary lymphatic angioendothelioma with partial "netlike" camouflage and D2-40 positivity was in arguement [21].

The etiology of RH remains obscure. Latent relations between malignant medical history and RH should be elucidated $[2,9]$. In this case no evidence supports the internal link between $\mathrm{RH}$ occurence and the past radiotherapy.

No tumor-related [8] deaths in RHs are observed under the circumstance of low metastasis. However, a locally invasive $\mathrm{RH}$ in China and a metastatic $\mathrm{RH}$ in a six-year-old girl turned out to be lethal [23]. Although adjuvant immunotherapy and radiotherapy have been proved to be effective in several cases, none agreed tumor-responding treatments are recommended unless a complete surgical excision is performed [24-27]. Amanda and her colleagues, however, proposed specific appearance on dermoscopy as practical assistance to diagnosis and therapy [28].

\section{Conclusions}

In summary, a case of $\mathrm{RH}$ situating on pleura has been depicted which exhibited peculiar pathological, immunological features and lesions. It has been reported as intrathoracic nodules predisposing a patient to unilateral pleural effusion. However discussion has been placed on the causes and treatment of RH. It implies that RH on location other than skin or subcutis may lead to corresponding symptoms or even threatened survival.

\section{Consent}

Written informed consent was obtained from the patient for publication of this Case Report and any accompanying images. A copy of the written consent is available for review by the Editor-in-Chief of this journal.

\section{Abbreviations}

$\mathrm{RH}$ : Retiform hemangioendothelioma; CEA: Carcino-embryonic antigen; HRCT: High resolution computed tomography; HE: Hemangioendothelioma; $\mathrm{EH}$ : Epithelioid hemangioendothelioma.

\section{Competing interests}

The author(s) declare that they have no competing interests.

\section{Authors' contributions}

QL collected the information and drafted the manuscript. RO attended the patient, arranged the clinical examination. PC participated in the medical decisions. $R Z$ revised the manuscript. All authors read and approved the final manuscript.

\section{Authors' information}

Qingqing Liu, Email: lqq.aileen@outlook.com Ruoyun Ouyang, Email: ruoyun001@126.com Ping Chen, Email: pingchen0731@sina.com

Rui Zhou, Phone: +86-731-5292100, Email: zhourui2355@sina.com

\section{Acknowledgements}

We thank Dr. Xia Wu at Department of Pathology and Dr. Juan Chen at Department of Radiology in the $2^{\text {nd }}$ Xiangya Hospital for offering information. We thank Prof. Hong Peng, Prof. Yan Chen at Department of Respiratory Medicine in the $2^{\text {nd }}$ Xiangya Hospital and Dr. Ye Gan at Yale University for helping drafting the manuscript. We thank Dr. Bowen Xie from the Center for Molecular Medicine of Central South University for editing the pictures. Special gratitude should be shown to Prof. Daiqiang Li at Department of Pathology in the $2^{\text {nd }}$ Xiangya Hospital and Prof. Jihe Li at Department of Pathology in the $1^{\text {st }}$ Xiangya Hospital for professional opinions in making the diagnosis. This study is financially supported by grants from the National Key Clinical Specialty Construction Projects.

Received: 30 June 2015 Accepted: 17 October 2015

Published online: 26 October 2015

\section{References}

1. O'Duffy F, Timon C, Toner M. A rare angiosarcoma: retiform haemangioendothelioma. J Laryngol Otol. 2012;126(2):200-2.

2. Albertini A-F, Brousse N, Bodemer C, Calonje E, Fraitag S. Retiform hemangioendothelioma developed on the site of an earlier cystic lymphangioma in a six-year-old girl. Am J Dermatopathol. 2011;33(7):e84-e7.

3. Weiss SW, Enzinger F. Epithelioid hemangioendothelioma a vascular tumor often mistaken for a carcinoma. Cancer. 1982;50(5):970-81.

4. Doyle LA. Sarcoma classification: an update based on the 2013 World Health Organization Classification of Tumors of Soft Tissue and Bone. Cancer. 2014;120(12):1763-74.

5. Requena L, Kutzner H. Hemangioendothelioma. Semin Diagn Pathol. 2013;30(1):29-44

6. Calonje E, Fletcher C, Wilson-Jones E, Rosai J. Retiform hemangioendothelioma. A distinctive form of low-grade angiosarcoma delineated in a series of 15 cases. Am J Surg Pathol. 1994;18(2):115-25.

7. Duke D, Dvorak AM, Harris TJ, Cohen LM. Multiple retiform hemangioendotheliomas: a low-grade angiosarcoma. Am J Dermatopathol. 1996;18(6):606-10.

8. Tan D, Kraybill W, Cheney RT, Khoury T. Retiform hemangioendothelioma: a case report and review of the literature. J Cutan Pathol. 2005;32(9):634-7.

9. Ioannidou D, Panaylotides J, Krasagakis K, Stefanidou M, Manios A, Tosca A. Retiform hemangioendothelioma presenting as bruise-like plaque in an adult woman. Int J Dermatol. 2006:45(1):53-5.

10. Schommer M, Herbst RA, Brodersen JP, Kiehl P, Katenkamp D, Kapp A, et al. Retiform hemangioendothelioma: another tumor associated with human herpesvirus type 8? J Am Acad Dermatol. 2000;42(2):290-2.

11. Aydıngöz IE, Mansur AT, Celasun B. Correspondence: Retiform hemangioendothelioma presenting as a hyperhidrotic tumor. Int J Dermatol. 2010;49(9):1076-7.

12. Darouti ME, Marzouk SA, Sobhi RM, Bassiouni DA. Retiform hemangioendothelioma. Int J Dermatol. 2000;39(5):365-8.

13. Fukunaga M, Suzuki K, Saegusa N, Folpe AL. Composite hemangioendothelioma: report of 5 cases including one with associated Maffucci syndrome. Am J Surg Pathol. 2007;31(10):1567-72.

14. Cronin P, Arenberg D. Pulmonary Epithelioid Hemangioendothelioma: an Unusual Case and a Review of the Literature. CHEST J. 2004;125(2):789-93.

15. Bhutoria B, Konar A, Chakrabarti S, Das S. Retiform hemangioendothelioma with lymph node metastasis: a rare entity. Indian J Dermatol Venereol Leprol. 2009;75(1):60-2.

16. Emberger M, Laimer M, Steiner H, Zelger B. Retiform hemangioendothelioma: presentation of a case expressing D2-40. J Cutan Pathol. 2009;36(9):987-90. 
17. Miettinen M, Wang Z-F. Prox1 transcription factor as a marker for vascular tumors-evaluation of 314 vascular endothelial and 1086 nonvascular tumors. Am J Surg Pathol. 2012;36(3):351.

18. Fukunaga M. Expression of D2-40 in lymphatic endothelium of normal tissues and in vascular tumours. Histopathology. 2005;46(4):396-402.

19. Parsons A, Sheehan DJ, Sangueza OP. Retiform hemangioendotheliomas usually do not express D2-40 and VEGFR-3. Am J Dermatopathol. 2008;30(1):31-3.

20. Fukunaga M, Endo Y, Masui F, Yoshikawa T, Ushigome S, Ishikawa E. Retiform haemangioendothelioma. Virchows Arch. 1996;428(4-5):301-4

21. Wachter DL, Agaimy A. A cutaneous vascular neoplasm with hobnail microscopic morphology and unusual gross features. J Cutan Pathol. 2012;39(4):454-7.

22. Guillou L, Calonje E, Speight P, Rosai J, Fletcher CD. Hobnail hemangioma: a pseudomalignant vascular lesion with a reappraisal of targetoid hemosiderotic hemangioma. Am J Surg Pathol. 1999;23(1):97-105.

23. Zhang G, Lu Q, Yin H, Wen H, Su Y, Li D, et al. A case of retiformhemangioendothelioma with unusual presentation and aggressive clinical features. Int J Clin Exp Pathol. 2010;3(5):528.

24. Hirsh AZ, Yan W, Wei L, Wernicke AG, Parashar B. Unresectable retiform hemangioendothelioma treated with external beam radiation therapy and chemotherapy: a case report and review of the literature. Sarcoma. 2010;2010:1-3

25. Choi WK, Lee SH, Oh SA, Kang DH. Retiform hemangioendothelioma on the finger. Arch Plast Surg. 2012;39(1):80-2.

26. Couceiro J, Sanders S, Manon-Matos Y, Banegas R. Retiform hemangioendothelioma of the finger: a case report. Hand Surg. 2013;18(03):439-41.

27. Al-Faky Y, Al-Mosallam A, Al-Rikabi A, Al-Sohaibani M. Medial canthus retiform hemangioendothelioma. Indian J Ophthalmol. 2014;62(4):491.

28. Mota A, Argenziano G, Zalaudek I, Piana S, Longo C, Moscarella E, et al. Clinical, dermoscopic and histopathologic findings of retiform hemangioendothelioma. Dermatol Pract Concept. 2013;3(4):11.

\section{Submit your next manuscript to BioMed Central and take full advantage of:}

- Convenient online submission

- Thorough peer review

- No space constraints or color figure charges

- Immediate publication on acceptance

- Inclusion in PubMed, CAS, Scopus and Google Scholar

- Research which is freely available for redistribution 